https://doi.org/10.48009/2_iis_2007_309-314

\title{
TOWARDS MODELING THE ECONOMICS OF PERSONAL RELATIONSHIPS IN DYADIC BUSINESS EXCHANGES
}

\author{
Reggie Davidrajuh, University of Stavanger, reggie.davidrajuh@uis.no \\ Øystein Jensen, University of Stavanger, oystein.jensen@uis.no
}

\begin{abstract}
This paper proposes modeling the economies of personal relationship so that its impact on the collective economic outcome in dyadic business exchanges can be measured. Firstly, this paper introduces personal relationship in business environment. Secondly, some of the parameters that are related to the issue of personal relationship are presented. Thirdly, a hybrid approach is proposed for developing a mathematical model; with the mathematical model, a better understanding of the impact of personal relationship on switching business exchange relationship and the costs involved (switching costs) can be understood and experimented with.
\end{abstract}

Keywords: Dyadic business exchange, personal relationship, mathematical model, switching cost

\section{INTRODUCTION}

In a dyadic business exchange environment, the relationship between two organizations is basically between two agents, and the relations can be a of a personal-relationship nature as the business relationship may grow to become personal one with time. On many occasions, in spite of the personal nature of the relationship, interacting agents are still able to coordinate their actions to bring economic benefits to their organizations.

However, the fact that selfish behavior of an agent may put his or her personal interest before the organization's benefit, demands the investigation of the loss of collective welfare due to selfish and uncoordinated behavior. Recent research efforts have focused on quantifying this loss for specific environments; the investigation of price anarchy has provided a number of measures by which is it possible to design social systems with robustness against selfish behaviors (Jensen, 2002; Namatame, 2006).

Structure of this paper: Section 2 presents some basic issues related to personal relationship in dyadic business exchanges. Section 3 seeks to identify the parameters involved in the personal relationships. Section 4 explores about the types of mathematics needed for building a mathematical model for personal relationship.

\section{PERSONAL RELATIONSHIPS IN BUSINESS EXCHANGES}

Business relationships (or relational contracts (MacNeil, 1980)) develop between organizations described as collective units on inter-organizational level, are only for the economic benefits of the organizations involved. Personal relationship or

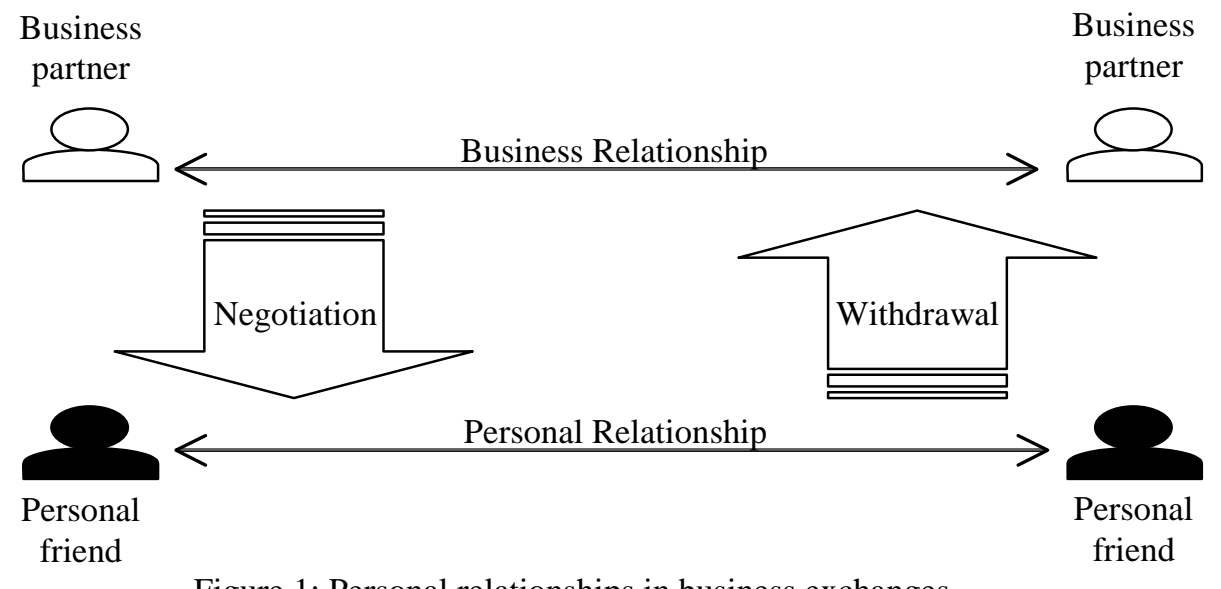

Figure 1: Personal relationships in business exchanges 
loyalty between two agents from otherwise independent organizations, may compromise the respective organizations interests (Jensen, 2002). The problem of loyalty is especially sensitive in contexts where the individual agents hold high-trust-posts (Giddens, 1991). High-trust-posts involve tasks that are executed beyond the direct surveillance of the central leaderships of organizations. In this case, the personal relationship between the individual agents becomes the decisive factor of the business relationship between the respective organizations. Thus, personal relationship can hamper economic profits that can be derived from the business exchange between the organizations.

\section{The Time Factor}

Personal relationships, stand alone or part of business relationships, take time to develop; see figures 1 and 2. When business relationships are to be developed quickly, the quality of personal interactions (relationships) may suffer due to stressful environment of relationship acceleration (Wilson, 1995); this phenomenon is also known as "timecompression diseconomies" (Dierickx and Cool, 1989).

\section{Switching Cost}

Personal relationship can also bring a business relationship to a stalemate at which conclusive decisions has to be taken whether to continue or discontinue the business relationship. The most important factor to be considered at this point is the cost of quitting (or switching cost) (Jensen, 2002).

Switching a business exchange relationship based on individual social contracts is considerably lower than for inter-organizational long-term commitments, such as strategic alliances. Relation-specific investments are first of all to be found in human asset specificity of the agents linking the organizations. The highest switching cost of individual social contracts is most likely to be as social costs between the individual agents involved. On organization-level these interpersonal costs are normally to be judged as low. Beside this qualitative analysis, however, there is no tool available to help an organization measure the switching cost of quitting a business exchange relationship that is dominated by personal relationship. Literature provides no mathematical models for this purpose; Lack of mathematical models for this purpose is mainly due to the adaptive nature of the economic agents and the uncertainties involved, and due to the complex nature of personal relationships involving huge number of parameters drawn from psychology, sociology, to management and economics.

\section{Guanxi}

Guanxi is a special case of personal relationships in

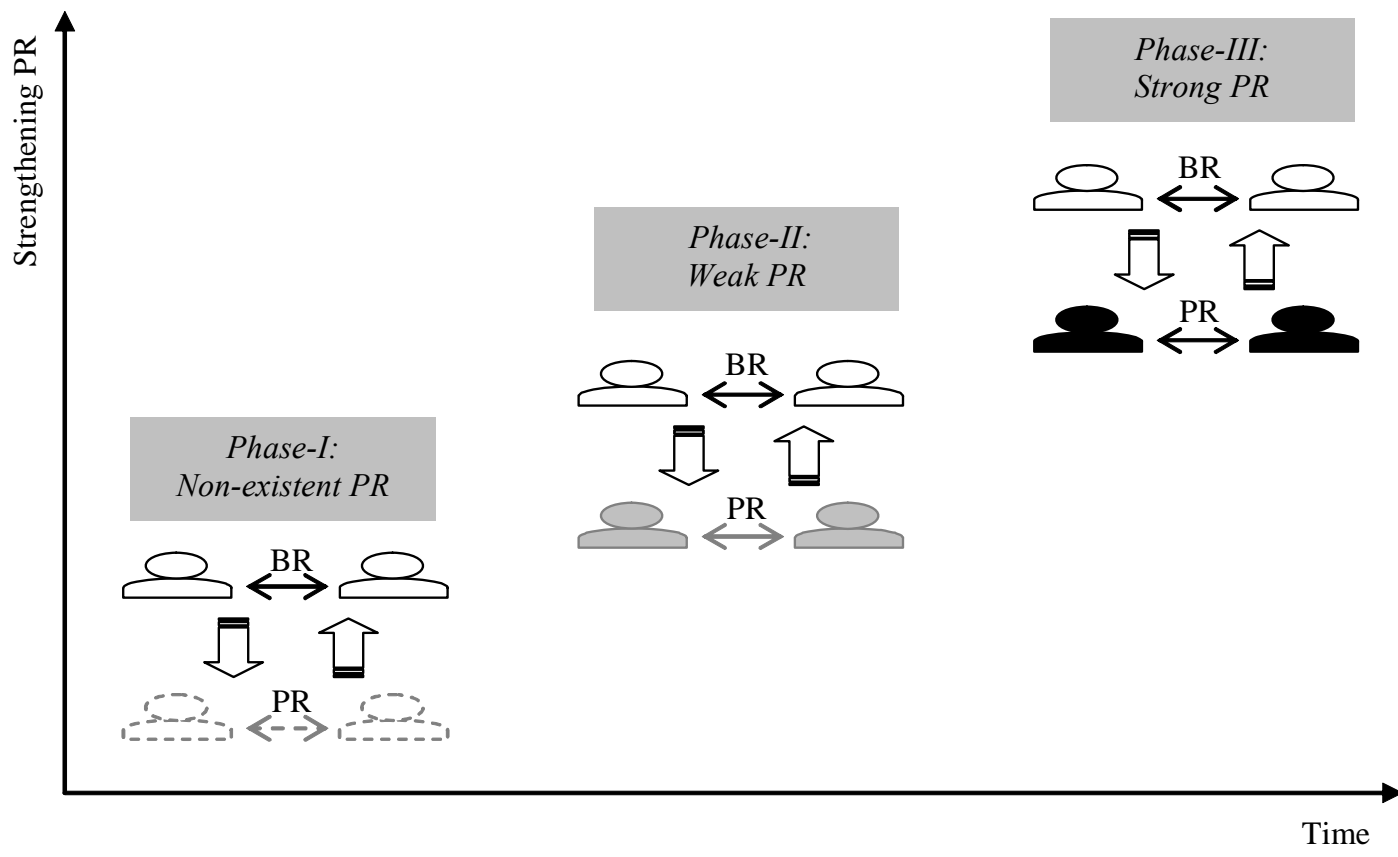

Figure-2: The time factor in establishing Personal Relationship (PR) 
business environment. The importance of developing personal relationship ('guanxi' in Chinese) in order to conduct business in China is well documented ( $\mathrm{Li}$ and Wright, 2000).

We say guanxi is a special case because in the guanxi system, there must be personal relationship before the business relationship can foster. However, in this paper, we focus on the personal relationship that develops because of the established (long-term) business relationship in an open market environment; see figure 2. As shown in figure 2, in the beginning, the relationship between two interacting agents is purely a business relationship; after long-term interactions, personal relationship can foster between the two agents, and if the personal relationship becomes the decisive factor in the business relationship, then we have a guanxi between the agents. In other words, with time, we move from open market system to guanxi system.

A closely related issue is the organization-toorganization guanxi (or popularly known as the "keiretsu", in Japanese language). In keiretsu, the "personal relationship" is not at the personal level, but at the organizational level (Miyashita and Russell, 1995).

\section{LITERATURE STUDY ON MODELING PERSONAL RELATIONSHIP}

Literature provides meticulous works on personal relationship in business exchanges, e.g. Chen (1994,1995), Davies, Leung, Luk and Wong (1995), Hwang (1987), Luo (1997) and Simmons and Munch (1996); see Lovett et al (1999) for a summary of the works. However, there is no serious work on mathematical modeling of the issue so that the switching costs can be calculated. Literature study on mathematical modeling of personal relationship found a crude model (Lovett et al, 1999) that has severe limitations: the model is static, timeinsensitive, and uses a limited set of parameters.

\section{Model by Lovett et al (1999)}

This is a simple model for calculating the difference between collective value of business exchange under the guanxi system which is influenced by personal relationship, and under the open market system which is free from personal influences.

An agent in personal relationship produces a fixed output in each period. The advantage of specialization in trade is that the output is more valuable if traded. The social surplus generated by individual $i$ :

$$
\begin{gathered}
S_{i}=(\text { untraded output })+(\text { value of traded output }) \\
-(\text { cost of production })-(\text { cost of contracting }) \\
S_{i}=Y_{i}\left(1-t_{i}\right)+\left(Y_{i} \times m \times t_{i}\right) \\
-\left(Y_{i} \times w\right)-\left(Y_{i} \times c \times t_{i}\right)
\end{gathered}
$$

where: $Y_{i}$ is the output of the agent, $t_{i}$ is the fraction of that agent's output that is traded, $m$ is the constant, greater than one, by which output increases in value when traded, $w$ is a constant marginal cost of production, and $C$ is the constant marginal cost of contracting.

Only two types of agents are considered in the model: New members (or juniors - J), and long-time members (or seniors - $S$ ). The total social surplus of the economy:

$$
\begin{aligned}
S_{T}=Y_{J} & \left(1-t_{J}+m \times t_{J}-w-c \times t_{J}\right) \\
& +Y_{S}\left(1-t_{S}+m \times t_{S}-w-c \times t_{S}\right)
\end{aligned}
$$

The guanxi system allows that juniors trade only a portion of their output; the seniors trade the whole output; in other words, $t_{J}<1, t_{S}=1$. In the market system, all agents are allowed to trade all of their output immediately, meaning, $t_{J}=t_{S}=1$

In addition, in the guanxi system, contracting costs are zero $(c=0)$, due to the trust between the interacting agents. In the market system, contracting costs are finite $(c>0)$.

The cost of switching is the difference between $S_{G}$ (the social surplus generated in the guanxi economy) and $S_{M}$ (the social surplus generated in the market economy):

$$
\begin{gathered}
S_{G}=Y_{J}\left(1-t_{J}+m \times t_{J}-w\right)+Y_{S}(m-w) \\
S_{M}=2 Y_{J, S}(m-w-c) \\
=>S_{G}-S_{M}=Y_{J}\left[\left(1-t_{J}\right) \times(1-m)+c\right]+Y_{S} \times c \\
\text { TOWARDS DEVELOPMENT OF A } \\
\text { MATHEMATICAL MODEL: } \\
\text { IDENTIFICATION OF THE PARAMETERS }
\end{gathered}
$$

\section{TOWARDS DEVELOPMENT OF A}

Modeling the economics of personal relationship in dyadic business exchange is no easy task as huge number of parameters is involved and due to the complexities in modeling the interactions between the agents. The first step of the modeling process is the identification of the parameters involved. The identification of parameters shown below is simplistic, but given as a starting point.

The stochastic model, denoted by $\boldsymbol{P}$, is an eight-tuple, 


$$
P=\left(G, B, E, D, C_{q}, O, t_{c}, \Psi\right)
$$

Where,

$G$ is the choice of governance form (contractual arrangements) of the business exchange (between buyers and sellers); there are mainly two governance norms:

Gc - Governance by collective social norms (inter-organizational)

Assumptions by GC (on institutional/collective level):

1. Mutual long-term commitment (solidarity)

2. Flexibility (continuous mutual adjustment)

3. Open information-sharing (mutual competence-development)

Gi - Governance by individual social norms (inter-personal)

Assumptions by $\mathrm{Gi}$ :

1. Inter-personal commitment (loyalty)

2. Flexibility

3. Limited information sharing

$B$ is the behavioral assumptions of the agents; the agents (as institutions) will try to optimize their long-term benefits achieved through the exchange relationships,

$E$ is the business environment variables linked to the situational context such as the characteristics of the external environment and the characteristics of the task structure of the exchange dyad,

$D$ is the dimensions of the situational contexts, such as:

1. Degree of complexity (produces static decision uncertainty of outcomes);

2. Degree of dynamics/volatility or turbulence which produces dynamic decision uncertainty of outcomes;

3. Values on risk (probability of loss or success)

$C q$ is the switching costs, which consists of: $c q b$ - loss of current benefits (direct and indirect)

Cqp - specific costs caused (triggered) by

the quit (problems/inconveniences)

Ce - costs by establishing new

relationships that has to be compared with,
$B e$ - expected benefits by the new exchange relationships

0 is the additional intersecting factors such as institutional and individual trust (social norms),

$t_{c}$ is the time-compression diseconomies, and finally

$\Psi$ is the high degree of perceived uncertainty among the agents and in the environment, caused by:

1) Volatility (dynamics/turbulence) in the external environment, and volatility in the task performance processes,

2) Uncertainties involved in the adaptive adjustments of the interactionprocesses of the exchange relationship

\section{DEVELOPING A MATHEMATICAL MODEL: A HYBRID APPROACH}

Due to the complex nature, this paper proposes a hybrid approach for the model building, utilizing three types of mathematics (figure 3): namely game theory, fuzzy logic, and discrete mathematics:

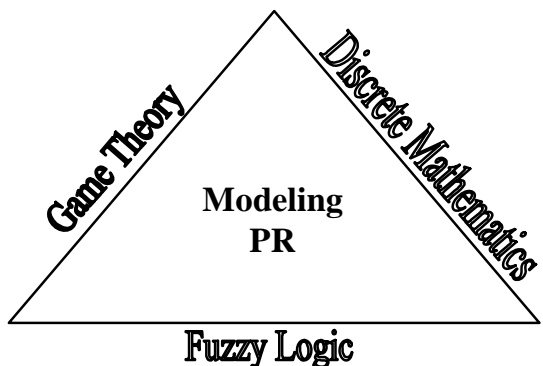

Figure 3: Hybrid approach for developing a mathematical model

\section{Game Theory}

Game theory is perfectly suited for modeling interaction between agents that are interacting over some issues or resources [Li et al, 2001; Fraser and Hipel, 1984]. In a non-cooperative situation ('game' in game theory), the possible courses of action available to the agents ('players') are referred to as options. Any set of options that can be taken by a particular agent is called a strategy. When each agent 
has selected a strategy, the result is referred to as an outcome.

An extension of game theory that is useful for modeling personal relationship is the theory of moves (TOM). The theory of moves was proposed to introduce a dynamic dimension to classical game theory [Li et al, 2001; Brams, 1994]. TOM extends strategic thinking into the more distant future by allowing the agents to think ahead not just to the immediate consequences of making moves (e.g. immediate business or personal outcome) but also to the long-term consequences [Li et al, 2001].

\section{Fuzzy Logic}

Though game theory and TOM are useful for our modeling purpose, the huge number of parameters need to be processed makes the modeling difficult, if not impossible. Thus, fuzzy logic can be used to obtain a level of abstraction to filter out the most important parameters from the less important ones, and to be able to work with less imprecise parameter values. There are many works that combines fuzzy logic with game theory [Kickert, 1978; Butnariu, 1978], particularly, the theory of fuzzy moves (TFM) - integrating fuzzy logic with the TOM.

\section{Discrete Time Model}

Personal relationships take time to develop; it is a continuous process. However, a discrete time model is more appropriate for modeling of personal relationship and its impact on business relationships; this is because, as with econometric models, the interactions between the agents are not monitored continuously but at certain intervals of time, in other words, in discrete-time. Discrete time games have been used in other fields too, e.g. in biotechnology [Radcliffe and L. Rass].

\section{CONCLUSION}

This paper proposes development of a mathematical model for understanding how the interaction between two agents leads to aggregate outcomes when personal relationship plays a major role in the business exchanges. In particular, the paper proposes research that deals with:

1. Modeling and computation: to contribute a new methodology and technique for modeling the economics involved in a dyadic business environment where personal relationship is involved in business relationships;
2. Simulations and experiments: building a mathematical model to reach a better understanding of the impact of personal relationship on switching a business exchange relationship and the costs involved (switching costs);

Once a mathematical model is developed, case studies can be done on dyadic business exchanges, especially in tourism trade where dyadic business exchanges are more common; the case studies can contribute to the discovery of new laws that govern complex economic and social systems. Mathematical model can also help the design and development of a new tool that can ease making decisions on switching a business exchange relationship.

\section{REFERENCES}

1. Brams, S. (1994). Theory of Moves, Cambridge, U.K.: Cambridge Univ. Press, 1994.

2. Butnariu, D. (1978). "Fuzzy games: A description of the concept,” Fuzzy Sets Syst., vol. 1, pp. 181-192, 1978.

3. Chen, M. (1994) Guanxi and the Chinese art of network building. New Asia Review, Summer: 40-3.

4. Chen, M. (1995) Asian management systems: Chinese, Japanese and Korean styles of business. New York, NY: Routledge.

5. Davies, H., Leung, T., Luk, S. and Wang, Y. (1995) The benefits of guanxi. Industrial Marketing Management, 24: 207-14.

6. Dierickx, I. and Cool, K. (989). Asset Stock Accumulation and Sustainability of Competitive Advantage. Management Science, 35 (December), 1504-1511.

7. Fraser, N. and Hipel, K. (1984). Conflict Analysis: Model and Resolution. New York: North- Holland.

8. Giddens, A. (1991). Modernity and self-identity: Self and Society in the late modern age. Cambridge/Oxford: Polity Press

9. Hwang, K. (1987) Face and favor: The Chinese Power Game. American Journal of Sociology, 92(4): 944-74.

10. Jensen, Ø. (2002). Benefits and drawbacks of dyadic inter-firm exchange dominated by individual social relationships versus collective, norm-based relationships. Marketing Networks in Global Economy, A joint symposium of EMAC and ANZMAC, Kuala Lumpur, December 2002.

11. Kickert, W. (1978). Fuzzy Theories on DecisionMaking. Boston, MA: Kluwer, 1978. 
12. Li, K., Karray, F., and Hipel, K. (2001). Fuzzy Apporaches to the Game of Chicken. IEEE Transcation of fuzzy systems. 9 (4), pp. 608-623

13. Li, J. and Wright, P. (2000) Guanxi and the realities of career development: a Chinese perspective. Career Development International, Vol. 5, Issue. 7, pp. 369-378

14. Lovett, S., Simmons, L., and Kali, R. (1999) Guanxi Versus The Market: Ethics and Efficiency. Journal of International Business Studies, Vol. 30 Issue 2, p231-247

15. Luo, Y. (1997) Guanxi and performance of foreign-invested enterprises in China: An empirical inquiry. Management International Review, 37(1): 51-70.

16. MacNeil, I. (1980). The New social Contract, an Inquiry into Modern Contractual Relations. New Haven, CT: Yale University Press.
17. Miyashita, K. And Russell, D. (1995) Keiretsu: Inside the Hidden Japanese Conglomerates. NY: McGraw Hill

18. Namatame, A., Lux, T., Axtell, R. (2006). Welcome to IJEIC. The Journal of Economic Interaction and Coordination, 2006 (1), pp. 1-3

19. Radcliffe, J. and Rass, L. (1997). Discrete time spatial models arising in genetics, evolutionary game theory, and branching processes.

Mathematical Biosciences, (140), 2, pp. 101-129

20. Simmons, L. and Munch, J. (1996) Is

relationship marketing culturally bound: A look at guanxi in China. Advances in Consumer Research, 23: 92-6.

21. Wilson, D. (1995). An Integrated Model of Buyer-Seller Relationships. Journal of the Academy of Marketing Sciences, 23 (4), 335-345. 